\title{
How Viagra Has Been Framed Since Its Launch: A Framing Analysis of Major Newspapers in South Korea and the USA
}

\author{
Eyun-Jung Ki* and Jangyul Robert Kim
} Department of Advertising and Public Relations, Collage of Communication and Information Services, University of
Alabama, Box 870172 Tuscaloosa, AL 35487-0172, USA

Department of Journalism and Technical Communication, Collage of Liberal Arts, Colorado State University, Fort Collins, CO 80523, USA

\begin{abstract}
This study was designed to compare the coverage of Viagra by newspapers in South Korea and the United States, considering that different sexual cultures exist in these two countries. A total of 421 articles from four major newspapers, Chosun Ilbo and Dong-A Ilbo in Korea and The New York Times and USA Today in the United States, were analyzed. It was found that Korean newspapers covered Viagra as a medical drug, whereas American newspapers more frequently framed Viagra as a social influencer. Also, it was determined that American newspapers more frequently drew information from drug manufacturers and patients, whereas Korean papers utilized experts, the government, and international or foreign news as their information sources. Further findings and implications also are discussed.
\end{abstract}

\section{INTRODUCTION}

The San Francisco Chronicle (1999) identified President Clinton's affair with Monica Lewinsky as the most popular American news story of 1998. The second most prevalent topic in the news that year was the introduction of Viagra. Following the launch of this new pharmaceutical, a multitude of stories sensationalized the drug and created an atmosphere in which the mere mention of its name became a public joke (Loe, 2004). With time, the blue pill became well known and generally well respected as an effective drug demonstrating consistent sales. Viagra continues to enjoy high visibility in the mainstream media, though currently for new reasons. Various news stories, including medical reports refuting what were believed to be hundreds of Viagra-caused deaths, have focused on the recreational use of Viagra.

Thanks to the variety and prevalence of mass media coverage, the majority of people in both South Korea and the United States may have been exposed to Viagra stories (Morganteler, 1999; Rubin, 2004). However, the media portrayal of the pill could vary between these two countries because the differences in their cultural perspectives on sexuality. Entman (1993) also asserted that "culture is the stock of commonly invoked frames; in fact, culture might be defined as the empirically demonstrable set of common frames exhibited in the discourse and thinking of most people in a social grouping" (p.53). Frames in these two countries should be different because culture causes the sets of common frames between the two countries to diverge. Despite the same product-related news coverage, similar product-related

*Address correspondence to this author at the Department of Advertising and Public Relations at the University of Alabama, Box 870172 Tuscaloosa, AL 35487-0172, USA; Tel: 205-348-0367;

E-mail:ki@apr.ua.edu news coverage of Viagra might be handled differently in South Korean and American newspapers due to the fact that this product is so closely linked to the culture of sexuality.

A great deal of research has been conducted on Viagra since its launch, including, but not limited to, the examination of the medical aspects (e.g., Carpiano, 2001), legal issues regarding insurance coverage (e.g., Keith, 2000; Klein \& Sturm, 2002), and the feminism approach (Loe, 2004). However, Viagra is more than a medicine; it is an influencer of cultural change. Despite the scope of this drug's influence and media coverage surrounding it, few scholars have attempted to determine how countries' differences in sexual culture affect their respective media coverage on Viagra. Thus, this study attempts to evaluate how news coverage of Viagra has been framed in the media in both America and South Korea, countries with disparate cultures of sexuality. The United States was chosen for this study because it is the country in which Viagra was developed and launched. South Korea was chosen among other Asian countries, which demonstrate a contrasting culture of sexuality to that of the United States, because the authors are more familiar with the country's culture, an essential component in the study. This study specifically examines how the coverage of Viagra in the two countries differs in terms of its medical drug frame and influencer frame. By examining how the media have covered Viagra in these two countries, this study may be able to identify the impact of culture on the media coverage of a given issue.

In considering how the issues of Viagra have been framed in American and South Korean print media, this paper will take the following structure: Part I provides a background on Viagra, an examination of the sexual cultures in the two countries being examined, and relevant literature related to framing studies. Part II describes the research method used in this study. Part III explains the results of a framing content analysis. The paper concludes with a discus- 
sion of study implications, research limitations, and suggestions for future research.

\section{LITERATURE REVIEW}

\section{Background of Viagra}

Taking its name from a combination of "vigor" and "Niagara," Viagra was initially discovered during the clinical testing process for a heart medication and was not originally developed for treatment of erectile dysfunction (ED). In April 1998, shortly after the Food and Drug Administration (FDA) granted approval, Pfizer Pharmaceuticals introduced Viagra, the first oral drug for the treatment of ED. It has been available by prescription to the American public since that time, and approximately 2.9 million prescriptions were filled during its first three months on the U.S. market (Lamberg, 1998).

In 1999, a year after its launch in the United States, the "blue pill" was introduced with popularity and controversy to South Korea. The Korean branch of Pfizer has distributed Viagra since then, and patients over the age 21 can purchase a monthly allowance of eight pills with written proof from a physician stating that they are free of cardiovascular disease (Choi, Ryu, Rha, \& Lee, 2001). From the time of its introduction to August 2004, more than 1.6 billion pills have been sold in South Korea.

Approximately 30 million men in the United States, and 100 million men around the globe, are affected by ED (Keith, 2000). More than 50 percent of American men between the ages of 40 and 70 suffer from some degree of ED (Feldman, Goldstein, Hatzichristou, Krane, \& McKinlay, 1994), while approximately 40 percent of Korean men suffer from ED (Lee, Oh, Yoo, Lee, \& Kim, 1989). By merely taking this new pill, patients may be able to resolve the insecurity issues related to the social stereotypes of ED, while eliminating inconveniences such as counseling and the embarrassment of talking to someone about their ED-related problems.

Because of its effectiveness in relieving such a profoundly personal affliction, Viagra became the fastest-selling drug in history, grossing over one billion dollars in its initial year of sales (Advertising Age, 2000). In 2002, Pfizer managed to accumulate worldwide sales of Viagra amounting to $\$ 1.7$ billion. In the same year, Pfizer became the fifth most profitable corporation in the United States.

Five years after Viagra's debut, the impact of the blue pill on American and Korean societies is quite visible. Before the pill's introduction, erectile dysfunction (ED) was a medical term primarily used only among medical experts. In the United States, several products such as Cialis and Levitra now compete for the ED market, and a new social phenomenon, "Viagra Babies," has been introduced (Tyre, 2004). The new pill has influenced Korean society as well. With the availability of the blue pill, the incidence of men using traditional folk remedies has decreased. For instance, the sales of Alaskan reindeer antler, which has been used as raw material for an ED folk remedy, decreased 87 percent between 1997 and 1998 (Kim, 2003). More importantly, the pill seems to have brought sexual discussions, formerly relegated to secrecy, into the South Korean public discourse.

\section{Cultural Background of Sexuality in South Korea and the United States}

Culture is a confusing and complex concept since it has at least two different meanings: "1) culture in the narrow sense of 'civilization' and its product, and 2) culture in the anthropological sense of broad patterns of thinking, feeling, and acting," which is much more inclusive than the first meaning (Hofstede, 1998, p. 5). In this study, the second meaning of culture is applied.

South Korea. Confucianism has continuously played a major role in Korean sexual culture. Since the Chosun dynasty, reproduction-oriented sexual norms have traditionally caused sexual acts to be regarded with total secrecy (Choi et al., 2001). This Confucianism taboo has been consistently dominant within marriage, in the family, and in public, tending to inhibit institutional sexual education programs. Many Korean children grow up with the belief that they should ignore sex and they are discouraged from discussing sexuality (Choi et al., 2001). This perspective on sexuality also influences the negative attitude toward the public discussion of sexual topics. However, this conservative approach and negative attitude regarding sexuality often results in reckless sexual activities among adolescents due to their natural curiosity and relative lack of knowledge about sex (Chung, 1990). In addition to that, the culture's negative beliefs about sexuality influence the prevalence of verbal and physical sexual domestic violence in Korea (Yi, 2001).

Another aspect influencing sexual culture in Korea is the male-dominant phallic orientation. Traditionally in Korea, the phallus is literally termed the "male-root", and the male sex is considered sexually superior to the female sex (Choi et al., 2001). Given this view, the phallus is worth consideration. Within this cultural perspective, men are raised to be and are portrayed as strong, aggressive, dominating figures, while women are encouraged to be passive and obedient to the males' dominant action. In the beginning of the $20^{\text {th }}$ century, however, Korean women started to enjoy greater equalities, politically, economically, socially, and culturally, which were spelled out in a Constitution. However, these equalities were not well always projected and maintained in reality (Choi, et al., 2001). Even though the gender inequality has decreased in the modern era, especially among the younger generation, it still exists. Although the Planned Parenthood Federation of Korea (PPFK) initiated sexuality education and consulting in 1968, formal sexuality education in schools has still not been well established (Choi, et al., 2001). Current sexual education in the country only emphasizes physical development and traditional gender roles. For example, the primary topics for female students are menstruation, pregnancy, and virginity, while those addressed for male students are sexual transmitted disease and sexual activities. Also, it is assumed that male students are sexually active but females should not be.

Korean males have traditionally taken folk remedies to improve their sexual vitality. For example, more than 70 percent of males who had erectile dysfunction regularly took some kind of popular traditional remedy such as snake soup 
(bam-tang) (Kim, 2004). One reason that the Korean government was concerned about Viagra and delayed sale of the drug in Korea was fear of greater misuse or abuse of the drug than might occur in other countries, due to a unique sexual culture in which men have traditionally turned to stimulants for increased sex drive and invigoration (Lee, 1999).

United States. Efforts to achieve, demonstrate, and prove masculinity are also rooted in American history, going back at least as far as the nineteenth century's self-made man (Kimmel, 1996). However, in the early twenty-first century, gender equity is now believed to be an increasingly achievable, and men are no longer the sole family breadwinners, and male power and control are no longer assured (Loe, 2004). Gender equality progressed in the U.S. during the sexual revolution that broke out in the 1950s, marked by such sexually monumental events as Kinsey's study Sexual Behavior in the Human Male (Kinsey, Pomeroy, \& Martin, 1948) and Sexual Behavior in the Human Female (Kinsey, Pomeroy, Martin, \& Gebhard, 1953)and the introduction of the birth control pill in 1960 .

Sex education programs have undoubtedly influenced the open discussion of sexuality in American culture. In the 1980 s, more than 85 percent of the American public approved the teaching of sex education in schools (Kenney, Guardado, \& Brown, 1989). By 1992, 17 states had mandated sex education and 30 more had recommended it (Haffner, 1992). In the 1920 s, sex education commonly dealt with premarital experience among the white middle-class. Later, courses on marriage and the family and sexual hygiene started to be introduced into the college curriculum. Additionally, marriage manuals began to emphasize sexual expression and pleasure, rather than sexual control and reproduction, and provided more explicit instructions about achieving satisfying sexual relationships (Choi et al., 2001).

\section{Framing Theory}

Framing theory has been used as a paradigm for understanding and investigating communication and related behavior in a wide range of disciplines (Rendahl, 1995). Studying mass communications through the concept of framing has become increasingly common in media studies (Aday, 2006; Chong \& Druckman, 2007; Edy \& Meirick, 2007; Entman, 1991, 1993, 2007; Reese, 2007; Zhou \& Moy; 2007). According to one of the most frequently quoted definitions of framing by Entman (1993), "to frame is to select some aspects of a perceived reality and make them more salient in a communicating text, in such a way as to promote a particular problem definition, causal interpretation, moral evaluation, and/or treatment recommendation for the item described" (p.52). Entman (1993) also stated that "frames define problems - determine what casual agent is doing with what costs and benefits, usually measured in terms of common cultural values; diagnose causes-identify the forces creating the problem; make moral judgments-evaluate causal agents and their effects; and suggest remedies - offer and justify treatments for the problems and predict their likely effects" (p.53). Frames are also defined as "organizing principles that are socially shared and persistent over time, that work symbolically to meaningfully structure the social world" (Reese, 2001, p.11).
Much of the research on framing has focused on how news stories articulate frames (Croteau, Hoynes, \& Carragee, 1996; Entman \& Rojecki, 1993; Gamson \& Modigliani, 1989; Gitlin, 1980). Others have approached framing as a reference (Scheufele, 1999), script, or schema that organizes the belief systems of a certain culture (Lodge \& Hamil, 1986), producing meaning and organizing experience (Gitlin, 1980; Tuchman, 1978).

Due to its influence on the press, culture cannot be ignored in framing analysis. For over a couple of decades, E. T. Hall has declared that the concepts of culture and communication cannot be separated. Culture is not only the context in which people dwell, but it is the essence of communication itself (Hall, 1966, 1976). Taking into account the influence of culture on the press, several studies have focused on framing related to cultural aspects or foreign news settings. For instance, Wanta and $\mathrm{Hu}$ (1993) identified two frames for foreign news: those that involve the United States and have a degree of conflict, and those that involve the United States but do not include conflict. Another study examined the coverage of the return of Hong Kong sovereignty to China from Britain (Zhang, 1998). By comparing the content of Xinhua, the official Chinese news agency, with that of the Associated Press, an American source, the author concluded that different frames found in the research result from the differences that exist between a culture with a capitalist/democratic system and a culture with a centralized, autocratic government and economy.

Other research has focused on the cultural aspect of framing. Hertog and McLeod (2001) approached frames as cultural phenomena. In Hertog and McLeod's research, frames are described as cultural structures with central ideas as well as more peripheral concepts. They stated that cultural phenomena carry extensive meaning that acts to culturally articulate individuals in diverse ways (Hertog \& McLeod, 2001). For example, cultural phenomena have tremendous symbolic power, and are relevant to the involvement of ego. An individual as a member of a society identifies with the morals, ideals, and definition of one's culture (Hertog \& McLeod, 2001). Also, the power of a frame's source is widespread recognition. Individuals, organizations and institutions act according to the presumption that members of the society share similar frames (Hertog \& McLeod, 2001).

A considerable number of drug framing studies have been conducted regarding the media coverage of crack cocaine and other drugs in the mid-1980s Danilian \& Reese, 1989; Hartman \& Golub, 1999; Johnston, 1989; Merrian, 1989; Reese \& Danilian, 1989; Shaw \& McCombs, 1989; Shoemaker, Wanta, \& Leggett, 1989. Although widespread media coverage of Viagra has propelled public discussion about sexuality (Morganteler, 1999), a review of the scholarly literature revealed no published studies examining media coverage of Viagra. The press does not merely transmit, but also frames and interprets messages within the contexts of shared cultural meaning (Haynes, 1984). It is difficult to discuss Viagra without involving sexuality. It is logical to assume that media in countries with disparate cultures of sexuality might vary in their coverage of the drug. By examining how media in countries with different perspectives on sexuality have covered Viagra stories, this study will deter- 
mine how framing is affected by culture an important yet often under-mentioned factor that has been missing in previous framing studies. Based on the exploratory nature of this study, the following research question was posed:

\section{RQ: HOW HAS VIAGRA BEEN FRAMED IN THE MAJOR NEWSPAPERS OF KOREA AND THE USA?}

\section{Methodology}

\section{Research Design \& Sampling Procedure}

A content analysis of major newspapers in Korea and America was conducted to examine how the issues surrounding Viagra have been covered. Korean newspaper articles were drawn from KINDS (Korean Integrated News Database System) ${ }^{1}$, the most comprehensive archival computer database in Korea. From the database, two major influential Korean newspapers with the largest circulations were selected: The Chosun-Ilbo, and The DongA-Ilbo. With a daily circulation of 2.38 million, Chosun $\mathrm{Ilbo}^{2}$ is the most widely distributed and read newspaper in South Korea followed by DongA Ilbo's ${ }^{3}$ with a circulation of about 2 million. American newspaper articles from two of the country's most influential newspapers, The New York Times and USA Today, were selected from Lexis Nexis, ${ }^{4}$ a database that allows one to search publications based on the daily circulation numbers. The daily circulation of New York Times is 1.1 million $^{5}$ and USA Today has a circulation of 2.27 million. ${ }^{6}$ Although circulation of the New York Times is smaller than that of USA Today, it is recognized as an agenda-setting source (Gitlin, 1980). These major newspapers were selected because they are the most significant influencer of public opinion among the three popular media forms, television, newspapers and magazines (Gitlin, 1980; Mazur, 1987; Reese \& Danielian, 1989; Shoemaker, Wanta, \& Leggett, 1989). Additionally, articles in the major newspapers of both countries are often reprinted by regional media sources. Thus, investigating their coverage patterns allows scholars to speculate on coverage trends followed by other smaller media sources in the two associated countries.

To gather sample articles for this study, a search on the KINDS and Lexis-Nexis databases were carried out searching for the term "Viagra" in story headlines. The search was limited to headlines because using a search extension to include appearance of the term in body text yielded too many unrelated articles. The time frame for article selection was from March 27, 1998 to September 26, 2004. The start date was chosen because it was the day that the FDA approved Viagra and stories about the medication began to appear in the media. The end date was chosen because it marked five years since the creation of Viagra. The searches yielded a total of 290 articles in the two Korean newspapers and a total of 131 articles in the two major American newspapers. This study analyzed all articles published in the four newspapers between March 27, 1998 and September 26, 2004, instead of using samples from the population.

${ }^{1}$ See http://www.kinds.or.kr

${ }^{2}$ See $\mathrm{http}: / /$ pr.chosun.com/chosun_english/numberchosun.asp

${ }_{3}^{3}$ See http://www.donga.com/docs/ilbo/job/2004/sub_a02_6.html

${ }^{4}$ See $\mathrm{http}: / /$ web.lexis-nexis.com

${ }^{5}$ See http://nyjobsource.com/nytimes.html

${ }^{6}$ See http://www.usatoday.com/media_kit/pressroom/pr_justfacts_usatoday.htm

\section{Coding Scheme}

Because no previous studies had done so, this study was designed to explore frames. In order to identify the frames, about 10 articles from each of the four newspapers were selected. The two major categories, "medical drug frame" and "influencer frame" were then identified. The medical drug frame indicates that an article describes Viagra solely as a medicine. The other category, "influencer frame," indicates that Viagra is described from cultural, political, and economic viewpoints.

Medical drug frame. The medical drug frame included three sub-categories: efficacy, information, and comparison frames. These three frames were also categorized by three tones: positive, negative and neutral. The articles identified as fitting into the efficacy category address Viagra's status as a miracle drug as well as its side effects, such as the accidental death of patients. The stories that fall under the positive type of efficacy are related to proof of efficacy, success cases, and positive effect of the drug. The stories categorized as negative efficacy are relevant to the drug's side effects, danger, and patient complaints etc. The neutral type of efficacy is efficacy-related stories not having either positive or negative stories in the same article.

The information frame articles report Viagra-related objective information such as the introduction of new ED drugs, related events, warnings and tips on ED, industry information, etc. This frame was also differentiated into three types based on the characteristics of the articles.

Comparison frame articles compare Viagra with competing ED drugs, such as Levitra, Cialis and other similar drugs. The three types were also analyzed. Stories addressing Viagra's superiority to other products were analyzed as positive and those referencing its inferiority were categorized as negative. Stories about Viagra's similarity to other products were regarded as neutral.

Influencer Frame. Viagra as an influencer frame was also divided into three sub-categories: sexual/cultural influencer, societal/political/legal influencer, and economic/environmental influencer. These frames were further categorized into three types, positive, negative, and neutral, based on the characteristics of the articles analyzed. Sexual/cultural influencer articles describe the influence of Viagra on people's sex lives and sex-related culture. Stories addressing the improvement of sexual performance were analyzed as positive whereas those that discussed the ethical damage the drug may cause to families or through misuse or abuse were categorized as negative. Political/Legal influencer articles describe the political and legal implications of Viagra. Stories about crime, lawsuits, fake products, and illegal distribution were analyzed as negative. Finally, articles that feel into the economic/environmental influencer category examine the economic and environmental impacts of Viagra. Summary of coding frame is shown in Table $\mathbf{1}$.

If article content presents multiple frames, it was coded as a major frame rather than being coded as multiple frames. Additionally, the types of information sources, the sections in which articles' were placed, and the countries covering the stories were also coded. The unit of analysis for the study was individual articles about Viagra. 
Table 1. Coding Frames

\begin{tabular}{|c|c|c|c|c|c|c|c|}
\hline & & & Medical Drug̨ & & & Influencer F & \\
\hline & Media & Efficacy & Information & Comparison & $\begin{array}{l}\text { Sexual/ } \\
\text { Cultural }\end{array}$ & $\begin{array}{c}\text { Societal/ } \\
\text { Political/Legal }\end{array}$ & $\begin{array}{c}\text { Economic/ Environ- } \\
\text { mental }\end{array}$ \\
\hline $\begin{array}{l}\text { त्ठ } \\
\stackrel{0}{0} \\
\tilde{E}\end{array}$ & Chosun Ilbo & & & & & & \\
\hline 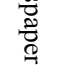 & Dong-A Ilbo & & & & & & \\
\hline 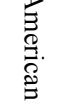 & NY Times & & & & & & \\
\hline 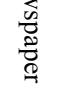 & USA Today & & & & & & \\
\hline
\end{tabular}

\section{Coder Reliability and Data Analysis}

Approximately 10 percent of all the data was doublecoded by a graduate student trained in qualitative and quantitative content analysis. Using Holsti's (1969) formula ${ }^{7}$, itemby-item inter-coder reliability ranged from 88.5 to 97.4 percent, which is acceptable. The overall reliability was found to be 92.4 .

For the analysis, two main statistical analyses were employed; descriptive statistics were used to identify the characteristics of data and Chi-Square was used to determine whether the two countries' frames were significantly different.

\section{RESULTS}

\section{Descriptive Statistics}

Figure 1 illustrates the distribution of the 421 news stories about Viagra in the two Korean newspapers $(\mathrm{N}=148$, $\mathrm{N}=142$, Chosun Ilbo and Dong-A Ilbo, respectively) and the two American newspapers ( $\mathrm{N}=88, \mathrm{~N}=43, N Y$ Times and USA Today, respectively) between the dates of March 27, 1998 and September 26, 2004. Korean newspapers published articles involving Viagra more frequently than did newspapers in the US. The amount of coverage reached its peak in both countries' newspapers during the initial period, the time following the FDA approval of the drug. However, after a few months, the volume of stories diminished rapidly, but continual coverage kept Viagra news on the media agenda in both countries throughout the next five years. While the frequency of coverage has been fairly steady in the American newspapers, it has fluctuated somewhat in Korean newspapers.

\section{Research Question}

The primary research question is concerned with how Viagra has been framed in the major newspapers in the two countries. Of the 290 articles from the Korean newspapers,

\footnotetext{
${ }^{7}$ Reliability $=2 \mathrm{M} / \mathrm{C} 1+\mathrm{C} 2, \mathrm{M}$ is agreement of the coders' coding decision, $\mathrm{C} 1$ and $\mathrm{C} 2$
} are the total number of coding decisions made by the two coders.
$51 \%$ adopted a medical drug frame $(\mathrm{N}=148)$ and $49 \%$ adopted an influencer frame $(\mathrm{N}=142)$. Of the 148 articles adopting medical drug frames, $13 \%$ covered the efficacy frame, $23 \%$ covered the information frame, and $16 \%$ covered the comparison frame. Of the 131 articles from American newspapers, $39 \%$ adopted a medical drug frame $(\mathrm{N}=51)$ and $61 \%$ adopted an influencer frame $(\mathrm{N}=80)$. Of the articles categorized in the medical drug frame, $12 \%$ of American newspaper articles adopted an efficacy frame, $18 \%$ adopted an information frame and $9 \%$ adopted a comparison frame. $24 \%$ of American newspaper articles categorized in the influencer frame adopted a sexual/cultural frame, $26 \%$ adopted a political/legal frame, and $11 \%$ adopted an economic/environmental frame. Chi-square test confirmed that the six sub-categories - efficacy, information and comparison under the medical drug frame and sexual/cultural, political/legal, economic/environmental under the influencer frame - are statistically different across the Korean newspapers and the American newspapers, as shown in Table $2\left(\chi^{2}\right.$ $=9.793, \mathrm{df}=5, \mathrm{~N}=421, \mathrm{p}=.081)^{8}$. Korean newspapers often discussed Viagra as a medicine, while American newspapers tended to discuss the pill within larger social and cultural contexts.

Further analysis was conducted to examine the sources of the information in the two countries' newspapers. As presented in Table 3, Korean newspapers tended to depend on international or foreign media, experts and government officials as their news sources $(\mathrm{N}=84,29.0 \%, \mathrm{~N}=66,22.8 \%$ and $\mathrm{N}=65,22.4 \%$, respectively). The major American newspapers more frequently relied on drug manufacturers and patients as their information sources $(\mathrm{N}=34,26.0 \%$ and $\mathrm{N}=23$, $17.6 \%$, respectively). The information sources are significantly statistically different $\left(\chi^{2}=73.591, \mathrm{df}=6, \mathrm{~N}=421\right.$, $\mathrm{p}=.000$ ).

Additional analysis investigated the various sections in which articles were placed in the newspapers of the two countries. As shown in Table 4, Viagra articles in Korean

\footnotetext{
${ }^{8}$ In order to run Chi-square statistics, it is required to have five objects in every cate-
} gory. 


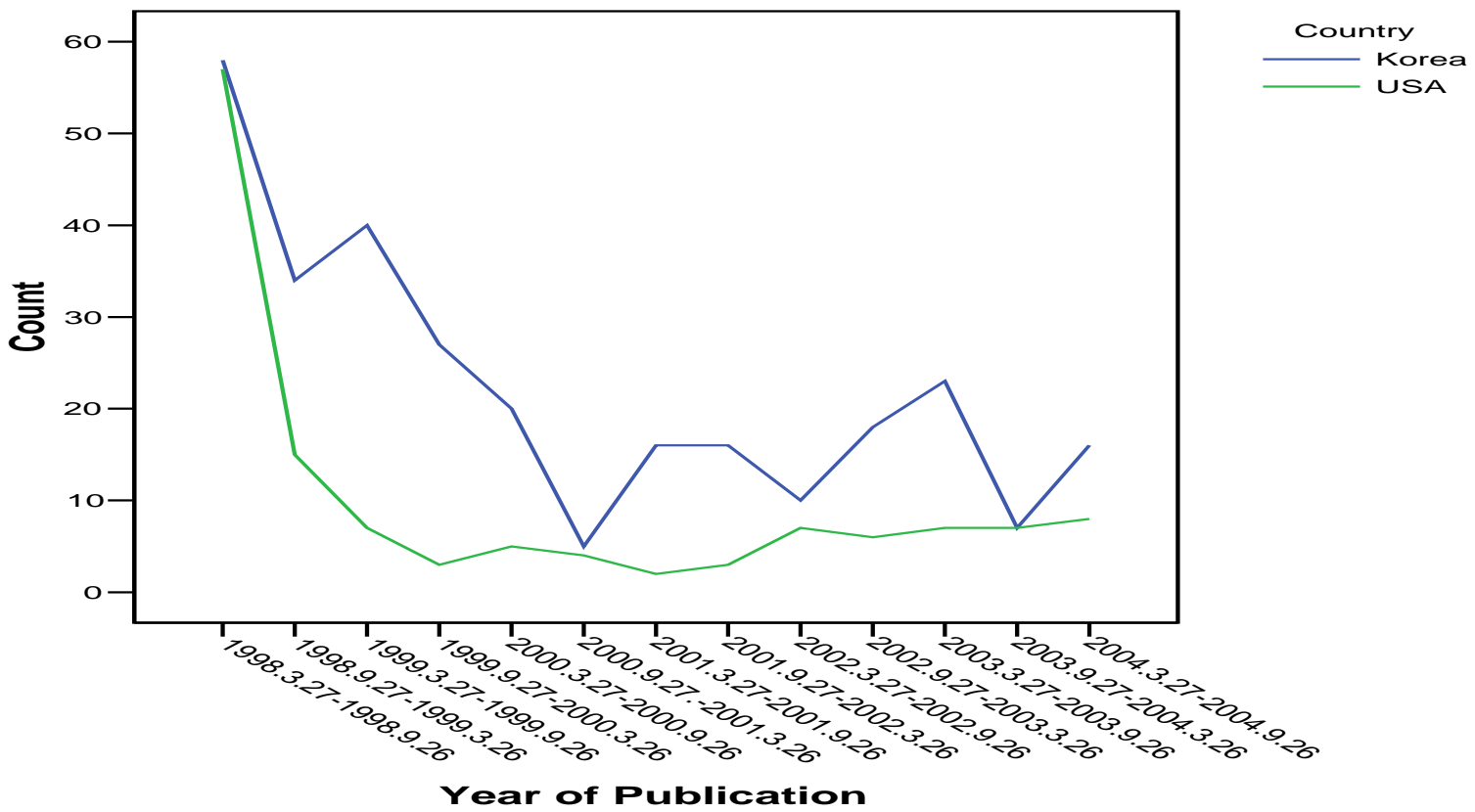

Fig. (1). Frequencies of Viagra Coverage.

newspapers most frequently appeared in the society and international sections $(\mathrm{N}=127,43.8 \%$ and $\mathrm{N}=54,18.6 \%$, respectively) and appeared relatively infrequently in the health section $(\mathrm{N}=1, .3 \%)$. Articles from American newspapers most frequently appeared in either the economy and business or society sections $(\mathrm{N}=42,32.1 \%$ and $\mathrm{N}=33,25.2 \%$, respectively) and least frequently in science/information section or international section ( $\mathrm{N}=3,2.3 \%$ for both).

Further analysis examined the degree to which each country covered its own country's news or other countries' news regarding Viagra. In American newspapers, the articles predominantly covered American news concerning Viagra $(\mathrm{N}=121,92.8 \%)$ rather than news about Viagra-related issues in other countries $(\mathrm{N}=10,7.7 \%)$. However, Korean newspapers dealt with the international impact of Viagra much more than the American newspapers $(\mathrm{N}=130,44.8 \%)$.

\section{CONCLUSION AND DISCUSSION}

This study was designed to compare the framing of Viagra by major newspapers in South Korea and the United States, considering that different sexual cultures exist in these two countries. As shown in Table 5, a total of 421 articles covering Viagra in the five years following the drug's approval for sale in the United States were chosen from four major newspapers in the two countries being examined. Although the volume of news stories about the drug dramatically decreased following the initial period, Viagra continues to enjoy media coverage since its launch. A particular issue's salience in the media agenda is usually evaluated in terms of the amount of media coverage it receives over time (Chyi \& McCombs, 2004), and the extensive coverage of Viagra has contributed to the popularity of the pill as a discussion point among the public. As Thomson (2006) indicated, the exten-

Table 2. Comparing Issues Covered by Korean and USA Newspapers

\begin{tabular}{|c|c|c|c|c|c|c|}
\hline Issue & \multicolumn{3}{|c|}{ Korean Newspapers } & & \multicolumn{2}{|c|}{ USA Newspapers } \\
\hline Medical Drug Frame & Frequency & & $\%$ & & Frequency & $\%$ \\
\hline Information & 66 & & 22.8 & & 24 & 18.4 \\
\hline Comparison & 45 & & 15.5 & & 12 & 9.1 \\
\hline \multicolumn{7}{|l|}{ Influencer Frame } \\
\hline Sexual/cultural & 40 & 13.8 & & 32 & & 24.4 \\
\hline Political/legal & 75 & 25.9 & & 34 & & 26.0 \\
\hline Economic/environmental & 27 & 9.3 & & 14 & & 10.7 \\
\hline
\end{tabular}

$\chi^{2}(\mathrm{df}=5, \mathrm{~N}=421)=9.793 \mathrm{p}=.081$. 
Table 3. Types of Information Source

\begin{tabular}{|c|c|c|c|c|}
\hline Types of Source & \multicolumn{2}{|c|}{ Korean Newspapers } & \multicolumn{2}{|c|}{ USA Newspapers } \\
\hline Experts & 66 & 22.8 & 31 & 23.7 \\
\hline Pfizer or other manufacturers & 43 & 14.8 & 34 & 26.0 \\
\hline Patient & 1 & .3 & 8 & 6.1 \\
\hline International News & 84 & 29.0 & 1 & .8 \\
\hline Others & 25 & 8.6 & 21 & 16.0 \\
\hline Total & 290 & 100 & 131 & 100 \\
\hline
\end{tabular}

$\chi^{2}(\mathrm{df}=6, \mathrm{~N}=421)=73.591 \mathrm{p}=.000$

sive media coverage of the blue pill shifted public discourse concerning male sexuality while expanding public understanding of male sexual problems.

The data analyzed revealed that news regarding Viagra has been continuously covered in both countries with varying frequency, especially in Korea. For example, the coverage of Viagra sharply increased between March 27, 1999 and September 26, 1999 as compared to the previous six months due to controversies about the sale of Viagra in Korean pharmacies during July 1999. A second distinct increase in the frequency of Viagra- related stories was found between March 27, 2003 and September 26, 2003 as compared with the previous publication patterns. Coverage frequency increased at this time due to the introduction of other competitive ED products, such as Cialis, to the market. Of the total 12 articles in the Korean newspapers during this time period, seven articles described other competitive products.

In response to the primary research question regarding how the media covered Viagra in Korea and the United States, Korean newspapers adopted a medical drug frame rather than a social influencer frame in their coverage of the pill. This finding indicates that Korean newspapers were still hesitant to publish sexual discussions related to Viagra in the media. Additionally, Korean newspapers seem more likely to consider Viagra a medicine in Korea, further implying that public discussion of sexuality is still discouraged. The cultural norm is reflected in the press, because culture influences the press, and press frames interpret messages within the context of shared cultural meaning (Haynes, 1984). Under the medical drug frame category, Korean newspapers covered efficacy, information, and comparison issues more frequently than American papers did. For example, a Chosun-Ilbo article from January 3, 2002 described the new ED products, Cialis and Levitra, comparing them with Viagra, based on function, effects, and ingredients, etc (Kim, 2002). American newspapers, on the other hand, were more open to publishing sexual issues related to Viagra. This finding indicates that Korean newspapers were more apt to cover functional and informational news about Viagra, including its effect, side effects, product information, etc., as compared with American newspapers.

Under the influencer frame category, American newspapers covered issues in the sexual/cultural and economic/environmental sub-categories more often than newspapers in Korea did. This finding implies that in the U.S., Viagra seems to be regarded not just as a medicine to cure patients' erectile dysfunction, but also as an influencer on the patient's social and sexual life. In terms of the societal/political/legal subcategory, both countries' newspapers

Table 4. Placement of the Articles

\begin{tabular}{|c|c|c|c|c|}
\hline Section where the article appeared & \multicolumn{2}{|c|}{ Korean Newspapers } & \multicolumn{2}{|c|}{ USA Newspapers } \\
\hline Health & 1 & .3 & 6 & 4.6 \\
\hline Society & 127 & 43.8 & 33 & 25.2 \\
\hline Economy or Business & 20 & 6.9 & 42 & 32.1 \\
\hline Opinion & 19 & 6.6 & 11 & 8.4 \\
\hline News & 33 & 11.4 & 32 & 24.4 \\
\hline Others & 3 & 1.0 & 1 & .8 \\
\hline Total & 290 & 100.0 & 131 & 100.0 \\
\hline
\end{tabular}


Table 5. Covering Countries

\begin{tabular}{|c|c|c|c|c|}
\hline Covering Country & \multicolumn{2}{|c|}{ Korean Newspapers } & \multicolumn{2}{|c|}{ USA Newspapers } \\
\hline Korea only & 160 & 55.2 & & \\
\hline USA and other countries & 125 & 43.1 & & \\
\hline Mixed & 5 & 1.7 & & \\
\hline Other country & & & 9 & 6.9 \\
\hline Mixed & & & 1 & .8 \\
\hline Total & & & 131 & 100 \\
\hline
\end{tabular}

covered a similar range. In Korean newspapers, however, news articles reporting crimes such as counterfeit Viagra products or its illegal importation were found more frequently, whereas articles regarding the social and political impacts of the drug were found more frequently in American newspapers.

Information sources used by the two countries' newspapers for Viagra news were also examined. The American newspapers more frequently used drug manufacturers and patients as information sources. This finding reflects the trend of American newspapers covering more issues with a sexual or cultural perspective because Viagra is considered to be both a medicine as well as an influencer on patients' lives. By contrast, Korean papers used experts (doctors or pharmacists), government sources, such as the Korean Food and Drug Administration (KFDA), and police and international or foreign news, such as the Associated Press (AP), as information sources. Selection of such news sources is due to the KFDA's control of imported medicine sales. Additionally, as stated earlier, Korean newspapers covered more crime-related issues, such as counterfeiting and illegal sales. In reporting these issues, police reports or prosecution investigation reports served as the main information sources.

Regarding the sections in which the Viagra articles appeared, Korean newspapers most frequently published these articles in either the international or the society sections, because the drug brought several social issues to light, such as crime, disuse, and abuse of the drug. The international section in the Korean newspaper featured articles from overseas reports involving the impact of Viagra in other countries. In American newspapers, most Viagra-related articles appeared either in the economy and business or the society sections.

Additionally, this study found that American newspapers focused primarily on national news concerning Viagra rather than news concerning the drug from other countries. However, Korean newspapers dealt with other countries' issues about Viagra much more due to the fact that it is an imported product.

\section{Limitations \&Future Research}

Like most studies, this research has several limitations that can inform future research endeavors. First, this study examined only major newspapers. Different results might be derived if other types of newspapers, such as financial newspapers (e.g. Wall Street Journal), had been examined. A greater variation of results could also be determined if other media formats such as television or magazines were considered. Second, tone, including positive versus negative, was not measured in this study. Therefore, future research could be improved by examining the difference in tone between articles from the countries being studied. Finally, researchers could potentially find different results by using different search strings to find articles. This study chose to limit the key word to "Viagra" and only applied it to a headline search. However, if future research incorporated additional search key words and extended the breadth of the search to a first paragraph or whole article search, other researchers might uncover more articles, thereby garnering different results.

\section{REFERENCES}

Pfizer now takes viagra hoopla to other countries. (1999). Advertising Age 90(9), 24.

Stories of the Year (1999). San Francisco Chronicle, p. A3.

Aday, S. (2006). The framesetting effects of news: An experimental test of advocacy versus objectivist frames. Journalism \& Mass Communication Quarterly 83, 767-784.

Caplan, P. (Ed.). (1987). The cultural construction of sexuality. London: Tavistock.

Carpiano, R.M. (2001). Passive medicalization: the case of Viagra and erectile dysfunction. Sociological Spectrum 21, 441-450.

Choi, H.-K., Ryu, J.-K., Rha, K.H., \& Lee, W.H. (2001). The International Encyclopedia of Sexuality: South Korea. Retrieved October 1, 2004 from http://www2.hu-berlin.de/sexology/IES/southkorea.html.

Chong, D., \& Druckman, J.N. (2007). A theory of framing and opinion formation in competitive elite environments. Journal of Communication 57, 99-118.

Croteau, D., Hoynes, W., \& Carragee, K.M. (1996). The political diversity of public television: Polysemy, the public sphere, and the conservative critique of PBS. Journalism \& Mass Communication Monographs 157, 1-51.

Danielian, L., \& Reese, S.D. (1989). A closer look at intermedia influences on agenda setting: The cocaine issue of 1986. In P. Shoemaker (Ed.), Communication campaigns about drugs (pp. 47-66). Hillsdale, NJ: Lawrence Erlbaum Associates.

Edy, J.A., \& Meirick, P.C. (2007). Wanted, dead or alive: Media frames, frame adoption, and support for the war in Afghanistan. Journal of Communication 57, 119-141.

Entman, R. (1991). Framing U.S. coverage of international news: Contrasts in narratives of the KAL and Iran Air incidents. Journal of Communication 41, 6-27.

Entman, R. (1993). Framing: Toward a clarification of a fractured paradigm. Journal of Communication 43, 51-58. 
Entman, R.M. (2007). Framing bias: Media in the distribution of power. Journal of Communication 57, 163-173.

Entman, R., \& Rojecki, A. (1993). Freezing out the public: Elite and media framing of the U.S. Anti-Nuclear movement. Political Communications 10, 153-173.

Feldman, H. A., Goldstein, I., Hatzichristou, D.G., Krane, R.J., \& McKinlay, J.B. (1994). Impotence and its medical and psychosocial correlates: Results of the Massachusetts male aging study. Journal of Urology 151(1), 54-61.

Gamson, W., \& Modigliani, A. (1989). Media discourse and public opinion on nuclear power: A constructionist approach. American Journal of Sociology 95, 1-37.

Gitlin, T. (1980). The whole world is watching: Mass media in the making and unmaking of the new left. Berkeley, CA: University of California Press.

Haffner, D.W. (1992). 1992 Report card on the States: Sexual rights in America. SIECUS Report 20, 1-7.

Hartman, D., \& Golub, A. (1999). The social construction of the crack epidemic in the print media. Journal of Psychoactive Drug 31, 423433.

Haynes, R.D. (1984). Test of Galtung's theory of structural imperialism. In R.L. Stevenson \& D.L. Shaw (Eds.), Foreign news and the new world information order. Ames, IA: Iowa State University Press.

Hertog, J.K., \& McLeod, D.M. (2001). A multiperspectival approach to framing analysis: A field guide. In S.D. Peese, O.H. Gandy \& A. E. Grant (Eds.), Framing public life: perspectives on media and our understanding of the social world (pp. 139-161). Mahwah, NJ: Lawrence Erlbaum Associates.

Hofstede, G. (1998). Masculinity and femininity: The taboo dimension of national cultures. Thousand Oaks, London: SAGE.

Holsti, O. (1969). Content analysis for the social sciences and humanities. Reading, MA: Addison-Wesley.

Johnston, K. (1989). America's drug problem in the media: Is it real or is it Memorex? In P. Shoemaker (Ed.), Communication campaigns about drugs (pp. 21-28). Hillsdale, NJ: Lawrence Erlbaum Associates.

Keith, A. (2000). Commentary: The economics of Viagra: A new blockbuster drug raises important questions about what is viewed as "medical necessity" bu insurers. Health Affair, March/April 147157.

Kenney, A., Guardado, S., \& Brown, L. (1989). Sex education and AIDS education in the schools: What states and large school districts are doing. Family Planning Perspective 21, 56-64.

Kim, C.J. (2002). "Viagra, stop there": New ED product sales. Chosun-Ilbo p. 50.

Kim, C.J. (2003). Viagra protects wild animals. The Chosun-Ilbo p. 62.

Kim, C.J. (2004). The fifth year of Viagra's birth which changed the quality of life (translated). Chosun Il-bo p. A12.

Kim, J. S. (2003). Sintoburi, Viagra: Korean Viagra is getting more popular, Hankook Ilbo p. 36

Kimmel, M. (1996). Manhood in America: A cultural history. New York: Free Press.

King, Y.J. (1987). Woman's four book (J.K. Kim, Trans.). Seoul: Myung Moon Dang.

Kinsey, A.C., Pomeroy, W.B., \& Martin, C.E. (1948). Sexual behavior in the human male. Philadelphia: Saunders.

Kinsey, A.C., Pomeroy, W.B., Martin, C.E., \& Gebhard, P.H. (1953). Sexual behavior in the human female. Philadelphia: Sanders.

Klein, R., \& Sturm, H. (2002). Viagra: A success story for rationing? Health Affair 21(6), 177-187.

Lamberg, L. (1998). New drug for erectile dysfunction boon for many, "viagravation" for some. JAMA 280, 867-869.
Lee, S.J. (1999). Will a special efficacy of Viagra happen in Korea as well? The Dong-A Ilbo p. 13.

Lee, H.S., Oh, B.H., Yoo, K.J., Lee, M.S., \& Kim, M.K. (1989). DSFI characteristics between normal and male sexual dysfunction. Journal of Korean Society for Human Sexuality 1, 83-93.

Lodge, M.G., \& Hanmil, R. (1986). A partisan schema for political information processing. American Political Science Review 80, 505-520.

Loe, M. (2004). The rise of Viagra: How the little blue pill changed sex in America. New York: New York University Press.

Mazur, A. (1987). Putting radon on the public risk agenda. Science, Technology and Human Values 12, 86-93.

Merriam, J. (1989). National media coverage of drug issue, 1983-1987. In P. Shoemaker (Ed.), Communication campaigns about drugs (pp. 2128). Hillsdale, NJ: Lawrence Erlbaum Associates.

Morganteler, A. (1999). Male impotence. Lancet 354, 1713-1718.

Padma-Nathan, H., Steers, W.D., \& Wicker, P.A. (1998). Efficacy and safety of oral sildenafil in the treatment of erectile dysfunction: A double-blind, placebo-controlled study of 329 patients. International Journal of Clinical Practice 52, 375-379.

Reese, S.D. (2001). Prologue--Framing Public Life: A Bridging Model for Media Research. In S.D. Reese, O.H. Gandy \& A.E. Grant (Eds.), Framing public life: Perspectives on media and our understanding of the social world (pp. 7-31). Mahwah, NJ: Lawrence Erlbaum Associates.

Reese, S.D. (2007). The framing project: A bridging model for media research revisited. Journal of Communication 57, 148-154.

Reese, S.D., \& Danielian, L. (1989). Intermedia influence and the drug issue. In P. Shoemaker (Ed.), Communication campaigns about drugs (pp. 29-46). Hillsdale, NJ: Lawrence Erlbaum Associates.

Rendahl, S. (1995). Frame analysis: From interpersonal to mass communication. Paper presented to Central State Communication Association, Indianapolis, Indiana.

Rubin, R. (2004). Men talking about Viagra: An exploratory study with focus groups. Men and Masculinities 7, 22-30

Scheufele, D.A. (1990). Framing as s theory of media effects. Journal of Communication 49(1), 103-122.

Shaw, D.L., \& McCombs, M.E. (1989). Dealing with illicit drugs: The power - and limits - of mass media agenda setting. In P. Shoemaker (Ed.), Communication campaigns about drugs (pp. 113-120). Hillsdale, NJ: Lawrence Erlbaum Associates.

Shoemaker, P., Wanta, W., \& Leggett, D. (1989). Drug coverage and public opinion, 1972-1986. In P. Shoemaker (Ed.), Communication campaigns about drugs (pp. 67-80). Hillsdale, NJ: Lawrence Erlbaum Associates.

Tuchman, G. (1978). Making news: A study in the construction of reality. New York: Free Press

Tyre, P. (2004). Viagra babies: Older parents, younger kids. Newsweek 6870.

Wanta, W., \& Hu, Y. (1993). The agenda-setting effects of international news coverage. International Journal of Public Opinion 5, 250264.

Zhang, Y. (1998). Covering the Hong Kong transition: A content analysis of the news stories by China's Xinhua news agency and the Associated Press of the United states between May 1 and August 31, 1998. Unpublished doctoral dissertation at the University of Kentucky, Lexington.

Zhou, Y., \& Moy, P. (2007). Parsing framing processes: The interplay between online public opinion and media coverage. Journal of Communication 57, 79-98.

Wimmer, D.R., \& Dominick, R.J. (2000). Mass media research: An introduction $\left(6^{\text {th }}\right.$ ed.). CA: Sage.

Received: March 11, 2008

Revised: July 13, 2008

Accepted: July 16, 2008

(C) Ki and Kim; Licensee Bentham Open.

This is an open access article licensed under the terms of the Creative Commons Attribution Non-Commercial License (http://creativecommons.org/licenses/by-nc/3.0/) which permits unrestricted, non-commercial use, distribution and reproduction in any medium, provided the work is properly cited. 